\title{
CERTAIN ANATOMICAL AND FUNCTIONAL INTERRELATIONS BETWEEN THE TEGMENTUM OF THE MIDBRAIN AND THE BASAL GANGLIA ${ }^{1,2}$
}

\author{
JOSHUA H. CAREY ${ }^{3}$ \\ Laboratory of Comparative Neurology, Department of Anatomy, \\ University of Michigan \\ NINE FIGURES \\ INTRODUCTION
}

This paper is an anatomical and experimental study of the location and the connections of certain selected areas of the macaque midbrain and forebrain. Lesions of the comparable areas in man produce involuntary movements (including tremor), loathness to move, rigidity and other disabilities which characterize the symptomatology of patients with a Parkinsonian syndrome.

\section{CONSIDERATION OF PERTINENT LITERATURE}

The areas and fiber systems which may show involvement in patients with the Parkinsonian syndrome are so numerous and so widespread that presentation of the pertinent literature adequately would imply writing an account of the anatomy, physiology and neuropathology of the midbrain, considerable

${ }^{1}$ Accepted in partial fulfillment of the requirement for the degree of Doctor of Philosophy at the University of Michigan.

${ }^{2}$ Some of the monkeys used in this experiment were made available through the kindness of Parke, Davis and Company, Detroit, Michigan. The necessary technical assistance was made possible by a grant given by the University of Michigan Medical School from the Hill Experimental Trust Fund. The author is very grateful for the assistance given him by Parke, Davis and Company and the University of Michigan Medical School.

${ }^{3}$ Author's present address is the Children's Hospital, 219 Bryant Street, Buffalo 22, New York. 
parts of the dorsal thalamus, the basal ganglia and the efferent parts of the cerebral cortex. Reviews of earlier literature (none of them complete) are to be found in volume 21 of the Research Publication for the Association of Nervous and Mental Diseases, which is devoted to a consideration of the diseases of the basal ganglia, and in the accounts by Wilson ('12, '14), Kodama ('26, '29), Aring and Fulton ('36), Ariëns Kappers, Huber and Crosby ('36) Woodburne, Crosby and McCotter ('46), Carpenter, Whittier and Mettler ('50) and Carrea and Mettler ('54, '55). The necessary clinical background for this study is provided in such neurological texts as those by Wilson ('41), Denny-Brown ('46), Grinker and Bucy ('49) and De Jong ('50).

In the present account certain papers which provide a relatively adequate background for placing the lesions or interpreting the results will be quoted. Those accounts which present corroborative material or points of view contrary to the present writer's interpretation will receive particular attention.

Wilson presented his historical account of lenticular degeneration in 1912 and two years later ('14), to provide anatomical and experimental evidence for his clinical work, studied experimentally the connections of the corpus striatum in the macaque. His results presented evidence for striatothalamic and thalamostriate fibers. He found no evidence for corticostriate connections.

Morgan ('27) based his conclusions on pathological material from human cases having basal ganglion involvements and on the results following experimental lesions in the corpus striatum of cats. His report deals with efferent fibers only. In addition to the usually described connections with the red nucleus and the subthalamic nucleus, Morgan traced fibers to the hypothalamus, to the interstitial nucleus of the medial longitudinal fasciculus and the nucleus of Darkschewitsch, to the oculomotor and Edinger-Westphal nuclei and, by a striatobulbar system, to practically all of the motor nuclei of the brainstem and the reticular formation. Such striato- 
bulbar connections have not been confirmed by later observers. Morgan reported that the operated cats showed athetosis, occasional tremor, homolateral hypertonicity and circus movements to the side of the lesion.

Ranson and his associates studied both the midbrain tegmentum and the basal ganglia with a view to establishing experimentally their connections and certain of their functions. Davenport and Ranson ('30) reported the nuclear configuration of the red nucleus, the subthalamic nucleus and adjacent tegmental areas in the rabbit and the cat. In 1932 Ingram, Ranson, Hannett, Zeiss and Terwilliger stimulated the tegmental areas in cats and monkeys. By use of the HorsleyClarke stereotaxic apparatus they obtained a turning of the animal's head, neck and trunk toward the side stimulated, or a flexion of the ipsilateral and an extension of the contralateral forelimb, or various movements of the hindlimb. Two years later, Ingram and Ranson ('34) placed lesions in the red nucleus of the cat. Following the operation the cat showed transient ataxia and incoordination of movements due undoubtedly to involvement of the superior cerebellar peduncles. There was a mild permanent hypertonicity of the extensor muscles but no tremor appeared. Keller and Hare ('34) described the effects of section of the rubrospinal tract in the region of the red nucleus. In addition to incoordination and ataxia they obtained an intention tremor which lasted only a few weeks. In 1942 Ranson and Ranson placed lesions in the head of the caudate, the putamen, the globus pallidus and the hypothalamus of macaques. They checked the position of the lesion in Marchi material. Those animals in which the ansa lenticularis and the lenticular fasciculus were involved at hypothalamic levels exhibited, postoperatively, a slowness and poverty of movement. Bilateral involvement of the globus pallidus produced no tremor, no ridigity, no slowness or poverty of movement and no masklike facies.

Later Ranson and his associates ('41) made isolated lesions in the corpus striatum of monkeys. The microscopic material prepared from the brain of these operated monkeys revealed 
only the pallidohypothalamic connections, distribution of fibers to the dorsal thalamus and some fascicles to the subthalamic nucleus. The connection described from globus pallidus to the habenula was probably not striatohabenular but the lateral corticohabenular fibers from the amygdala and the gyrus hippocampi.

Aring and Fulton ('36) elicited action tremor — such as was obtained by the present observer in stimulation of the midbrain tegmentum - by removal of the cerebellum in two baboons and 14 macaques. Ferraro and Barrera, in the same year, obtained a resting tremor by large lesions in the tegmentum of the macaque.

Kennard ('44) placed lesions in the basal ganglia of various primates by sucking out portions of the area following a direct approach through the cortex. Bilateral injuries to the caudate and to the putamen produced bilateral tremor often more in the head than in the arms. Lesion of one globus pallidus alone gave no results but addition of lesions in area 8 resulted in tremor (sometimes bilateral) and in spasticity. Choreoathetoid movements appeared contralateral to the destructions in these experiments; such destructions involved considerable portions of the cortex so that it is difficult to evaluate the results.

Several studies on the functions and connections of the basal ganglia have been presented by Mettler and his associates ('42, '47). Mettler and Whittier ('47) placed lesions in and around the subthalamic nucleus in 71 monkeys. In 19 monkeys in which the subthalamic nucleus was involved, persistent choreiform, athetoid or choreoathetoid movements were present. Tremor, ipsilateral to the subthalamic involvement, also appeared. The animals with basal ganglion lesions had hyperkinesia. In a later paper ('49) Whittier and Mettler described the paths involved in the subthalamic lesions. They obtained evidence for connections of the subthalamic nucleus with globus pallidus, substantia nigra and the dorsal thalamus - apparently nucleus ventralis lateralis. In 1950 Carpenter, Whittier and Mettler gave a graphic method of studying 
the tremor produced in monkey by diencephalic lesions. A detailed account of the distribution of the superior cerebellar peduncles in the monkey is to be found in the 1954 paper by Carrea and Mettler. In a later recent paper ('55) the authors presented an extensive study of the results of lesions in and around the brachium conjunctivum, before, during and after its decussation. The lesions of the brachium conjunctivum in the midbrain tegmentum produced, on the side of the lesion, an ataxic tremor, a hypokinesia and a circling toward that side. Lesions in the decussation of the brachia conjunctiva, or rostral to the decussation, or in the magnocellular part of the red nucleus, produced like results. Tremor alone resulted when only the ventral part of the brachium was sectioned.

The neuroanatomy group at Michigan also have contributed to the anatomical relations of the areas under consideration. The nuclear pattern on the midbrain tegmetum was described by them (Huber et al., '43) for a series of mammals including monkey and man (see particularly paper by Crosby and Woodburne, '51). The interrelations between the basal ganglia and the tegmentum of the midbrain (Woodburne, Crosby and McCotter, '46) and the hypothalamotegmental pathways (Crosby and Woodburne, '51) were described in some detail, and the results obtained checked with the literature. A paper by Rand ('54), contains a detailed account of the distribution of the superior cerebellar peduncle to the midbrain tegmentum and the dorsal thalamus. Laursen ('55) reported on the effect of lesions in the globus pallidus of the monkey. Two of his results are of particular interest. He demonstrated some direct fibers from the globus pallidus to the capsule of the red nucleus by way of the lenticular fasciculus. He also produced a monkey which exhibited marked loathness to move. In this monkey the lesion involved the subpallidal region as well as the globus pallidus.

In a series of experimental stimulations of the macaque tegmentum in midbrain and pons, beginning in front of the red nucleus and continuing spinalward to a plane just rostral 
to the level of the abducens nucleus, Jenker and Ward ('53) obtained, rostrocaudally and successively, a tremor of the following regions: (a) the contralateral fingers and toes; (b) the contralateral cheek, chin and lower lip; (c) the contralateral hand; (d) the upper and lower lips. The tremor persisted for a short time after the stimulation ceased. The exact points of stimulation were not indicated although the whole area stimulated was figured.

On the clinical side innumerable articles have dealt with the Parkinsonian syndrome since the original article was written by Parkinson (1817) entitled "An Essay on Shaking Palsy." This paper by Parkinson presented so completely the clinical picture that succeeding accounts, as Wilson (41) pointed out, have added little to this early description.

Gordon Holmes ('04) described 9 cases of Parkinsonism (two with autopsy reports) seen in his own practice and a number of similar cases reported in the literature. He concluded that the action tremor was associated with a lesion in the cerebellorubral system.

\section{MATERIALS AND METHODS}

The animals used for these experiments were partly Macaca mulatta and partly Macaca cynmologus. The weight ranged from about $2.2 \mathrm{~kg}$ to $5.5 \mathrm{~kg}$. Their ages were approximately one to three and one half years. Five were male and 4 were female.

Great care was taken to select monkeys which were in good general condition for the experiments. They were tested preoperatively and found to have normal voluntary movements, normal deep reflexes, and absence of Babinski reflexes and muscle tone within the normal range. They showed no observable signs of cortical, basal ganglia or cerebellar involvement, and no involuntary movements or tremor. They were active and alert. Their behavior was recorded in moving pictures.

The animals were operated on for survival and so sterile technique was employed. The deep stimulations and lesions 
were placed by use of a sterotaxic instrument (McCulloch modification). The lesions on the surface were made by trephining the skull over the area to be operated upon, opening the dura, identifying the area and then removing it by suction. The dura was carefully sutured, and the muscle, fascia and skin closed in layers. Most of these monkeys were given a subcutaneous dose of $1 \mathrm{mg}$ of morphine sulfate and $0.1 \mathrm{mg}$ of atropine sulfate about 45 minutes before the operation began. The monkey was anesthetized throughout the operation by ether given by the open cone method. This permitted varying the depth of anesthesia at will.

In all experiments where the stereotaxic instrument was used, stimulation was employed before any lesions were made. Stimulation was provided by a Grass stimulator, Model C, and the details of the voltages are given in the individual protocols. The frequency of the current for stimulation was 40 with a duration of $1 / \mathrm{ms}$. Monopolar electrodes and rectal plug were used in stimulation. The lesions were placed with the same Grass instrument using the amperage of 400 microamperes usually for 60 seconds. During the operation the respiration was checked for changes in rate, depth and regularity.

Before stimulation or the placing of destructive lesions the drapes were so arranged that the face, trunk and extremities of the animal were exposed to view. The head was fixed in the stereotaxic instrument. Careful observations were made with respect to movements of any type including those of athetoid character or tremor. Any such movements which appeared to the observer to be significant were photographed with the moving picture camera.

Tests made immediately at the end of the operation were found not to be valid because of the influence of the anesthetic. Detailed testing was not attempted until the first postoperative day. From then on the testing was done frequently during the survival period of the animal or until another operation was performed. The postoperative observations consisted of checking for the appearance of pyramidal tract 
signs (such as a Babinski and changes in deep reflexes), the possible appearance of ataxias or other changes in locomotion, variations in muscle tonus and the possible occurrence of involuntary movements or tremor. The animals were also watched closely to determine any deviation from normal behavior, especially in respect to alertness and amount of activity. Moving pictures were taken to record any significant changes in behavior from that shown preoperatively.

All the animals were operated on more than once. In some cases (see protocols) comparable lesions were placed bilaterally. In other cases a succession of different lesions were placed in the same animal to aceentuate or modify the results first obtained.

When the animal was sacrificed the brain was perfused with neutral formal (10-15\%). It was then removed from the skull, examined grossly and prepared by the Swank-Davenport modification of the Marchi technique. Microscopic checking of the location of the lesions and the degenerating fiber paths was carried out.

\section{REPORT OF EXPERIMENTS}

\section{Monkey No. 1}

This was an alert female Macaca cynmologus weighing $1.9 \mathrm{~kg}$ and with no neurological signs.

First operation (10-9-53) and postoperative testing. The animal was operated upon after being anesthetized in a stereotaxic machine. The needle was inserted in the left substantia nigra in accordance with previously determined readings. The stimulation was made at 4 volts. There was no evident response. Lesions were placed at three levels of the substantia nigra.

On the third postoperative day the animal was sluggish, lethargic, weak and hypotonic. The right pupil was smaller than the left but both reacted to light. There was no change on the 4th postoperative day; on the 5th day the animal still showed some hypotonicity and lethargy.

Second operation (10-16-53) and postoperative testing. Using the same readings as in the preceding operation but to the right of the midline, the stereotaxic needle was again placed in the substantia nigra. Neither stimulation nor the lesions placed immediately after 
such stimulation produced any neurological changes. On removal from the machine the animal showed a tendency to turn to the left.

On the first postoperative day the animal had a mild weakness and hypotonicity in the left upper and left lower extremities. There was some lethargy but no pupillary changes. The weakness persisted until the animal was sacrificed. On the 4 th postoperative day the monkey exhibited a few myoclonic movements.

Microscopic report. The monkey was sacrificed on 11-13-53. The brain was prepared by the Marchi technique. The microscopic preparations made from the brain of monkey no. 1 showed a very small Iesion in the caudate nucleus on the right side (fig. 1, right). This lesion has an anteroposterior extent of about $1 \mathrm{~mm}$. A few fibers in the posterior limb of the internal capsule (fig. 1, right) are also damaged. There is a small lesion in the right optic tract, and, at the same level, a slight involvement of the right subthalamic nucleus. This last lesion increases somewhat caudally. Small areas of destruction are present in the right globus pallidus (fig. 1) and the right. red nucleus and a needle track through the left globus pallidus (fig. 2).

\section{Monkey No. 2}

This animal was an active male Macaca mulatta weighing $4.1 \mathrm{~kg}$ and with no neurological signs.

First operation (10-27-53) and postoperative testing. The animal was anesthetized and placed in the stereotaxic machine. The needle was inserted in the right substantia nigra in accordance with previously determined readings. The stimulation was made at $3-6$ volts. Voltages of 4 and above caused slowing of respiration at all readings. Lesions were placed at all readings.

On the first postoperative day the monkey showed hyperactive left knee jerk, mild weakness and hypotonicity in the left leg, and poor placing reactions of the left foot.

Second operation (11-10-53) and postoperative testing. The operative procedure was the same as for the first operation except that the readings were for the right red nucleus. The stimulation was made at $3-6$ volts. At all voltages and all readings the left upper extremity showed rigidity. This extremity also showed fine tremor but flexed only at the rostral readings. At the most caudal reading it showed some extension at both wrist and elbow. At the highest voltage there was some generalized trembling of the body, suggesting that the combined voltage and frequency were too great. Lesions were placed at all readings. When the most rostral lesion was placed, respiration ceased for three seconds. It reasumed when the current was turned off but remained shallow throughout the experiment. 
When the placing of this rostral lesion was begun there was an increase in flexion at the left elbow, the left fist was clenched and the whole extremity became more rigid. Then, as the lesion increased, the extremity relaxed to some extent and a fine alternating tremor appeared which persisted after the current was turned off. Immediately after operation there was increased tonus in the left upper extremity with the elbow in flexion and the fist clenched. There was no cogwheel rigidity. There was a fine tremor in both left extremities. On the first postoperative day the monkey had mild, jerky, somewhat uncoordinated movements with hypotonicity in both left extremities and attacks of action tremor in the left lower extremity. On the 4th postoperative day the tremor had disappeared but there was some reduction of tone in the lower left extremity. On the 7 th postoperative day there was no change from the previous examination.

Third operation (11-17-53) and postoperative testing. The operative procedure was the same as for the previous operation except that the readings were for the left red nucleus. On stimulation of the most rostral point the left eyelid elevated. Obviously oculomotor fibers were being stimulated. No other responses were obtained on stimulation, except a slowing of the respiratory rate. A lesion was placed at each reading. Nothing was noted during the placing of the lesions except some interference with respiration.

Immediately after the operation both left extremities were hypotonic. There was a very fine action tremor in the left lower extremity. Later in the same day a periodic myoclonic contraction of the shoulder museles causing bilateral shrugging of the shoulders was noted; also the animal ground his teeth at intervals. On the first postoperative day the animal was more aggressive than before any of the operations. His left pupil was enlarged and fixed to light and there was a mild ptosis on the left, both indications of oculomotor involvement. He also showed a mild hypotonus of the right lower extremity. The convulsive attacks of shrugging of the shoulders and grinding of the teeth still appeared at intervals. During these attacks he also threw back his head and closed his eyes. He oceasionally showed, after activity, a fine intention tremor of the left lower extremity. On the 6th postoperative day the convulsive attacks persisted and there was increased tone in the left upper extremity. The other signs were the same as on the first postoperative day. On the 8th postoperative day he developed a right torticollis. On the 13th postoperative day the torticollis and rigidity had disappeared but the convulsive attacks remained; a fine intention tremor was present in both left extremities. On the 14th postoperative day the signs were the same except the ptosis of the left eyelid had cleared up. The left pupil still remained fixed. 
Fourth operation (12-4-53) and postoperative testing. The operative procedures were the same as in the previous three operations except that the readings were for the left globus pallidus. During stimulation at the most anterior lateral reading, respiration slowed and then ceased for a brief period. The respirations were restored when the stimulation was discontinued. On the second postoperative day the animal showed convulsive attacks of the nature of petit mal and also generalized clonic spasms of all 4 extremities and the neck. The deep reflexes were increased on the right in the lower extremity. There were no paresis and no Babinski signs. When he walked, he showed mild incoordination of movement in all members. All extremities were mildly hypotonic except the left upper extremity which showed mild rigidity. He had an action tremor in both upper extremities, was lethargic and exhibited marked loathness to move. On the 11th postoperative day the findings were the same as on the second day.

Fifth operation (12-17-53) and postoperative testing. The operative procedures were the same as in the previous experiments except that the readings were for the right globus pallidus. Other than irregularities in the respiratory rate no effects of stimulation or of the placing of the lesions were observed. On the first postoperative day the animal exhibited a generalized weakness, a left hemiparesis and increased reflexes in both lower extremities but no Babinski sign. He had rigidity in all 4 extremities but it was more marked on the left side. He retained a fine action tremor in all 4 extremities and had clonic spasms of all extremities and the neck, comparable to those seen clinically in Wilson's hepatolenticular degeneration. The loathness to move increased after the fifth operation.

Microscopic report. The monkey was sacrificed on 12-18-53. The brain was prepared by the Marchi technique. The needle tracks for the lesions involving the globus pallidus go through area 6 . On one side there is some indication of an involvement of the ventromedial portion of the globus pallidus (fig. 3, right) and of its lateral part (not illustrated). The lesion also extends into the optic tract (fig. 4 , right) and into the area ventral to the globus pallidus so that it interrupts the corticopallidohypothalamic fibers. There are also lesions in the posterior limb of the internal capsule on both sides (fig. 3). From these lesions degenerated fibers can be traced caudalward through the brain stem. Internal to the cerebral peduncle near the junction of the diencephalon and mesencephalon there is an injury to the substantia nigra on the right. The red nucleus and the area ventromedial to it are almost completely destroyed bilaterally. The destruction on both sides - but particularly on the right - is il- 
lustrated in figure 5. The Marchi material did not cut well at these brain levels; consequently the photomicrographs are not entirely satisfactory.

\section{Monkey No. 3}

The third animal was a male Macaca mulatta that was belligerent, active and alert with no neurological signs. He weighed $3.5 \mathrm{~kg}$.

First operation (1-12-54) and postoperative testing. This animal was operated upon after being anesthetized and placed in the stereotaxic machine. The needle was inserted in the right red nucleus in accordance with previously determined readings. Stimulations were made at 3-6 volts. At all readings on stimulation of 4-6 volts, the left arm flexed at the elbow and wrist and showed rigidity for the duration of the stimulus. When the stimulation ceased the arm relaxed and a fine tremor appeared. No tremor of the trunk or lower extremities was noted during the operation. Lesions were placed at all readings. During the production of the lesions the left arm extended with the fist clenched; a fine tremor of the left leg and the muscles of the belly on the left side appeared. This tremor persisted. The left arm relaxed and a fine tremor appeared in it after the coagulation current was discontinued. On the second postoperative day there was a mild hypotonicity of the left arm and left leg. A fine tremor was present in the left leg, but none was noted in the left arm. Every one or two minutes the monkey yawned and ground his teeth. He had attacks of myoclonic spasm of the left side of the face and body, beginning with the shoulder. Moreover, his movements as a whole were more jerky in character than before operation. On 6th postoperative day the monkey had become quite aggressive; the hypotonicity was greatly reduced. The fine tremor continued but was less than on the second postoperative day. The yawning and myoclonic movements were greatly abated but the voluntary movements were still less smooth and coordinated than preoperatively.

Second operation (1-19-54) and postoperative testing. The procedures were the same as in the first operation except that the needle was inserted in the left red nucleus. No tremor or changes in respiration were noted during stimulation. After the lesions were made, the animal showed a generalized tremor and rigidity of all 4 extremities; these signs disappeared in a few hours. On the first postoperative day a mild, intermittent action tremor was present. On the 10 th postoperative day the animal had an action tremor in all 4 extremities but there were no indications of an increased tonus of the muscles. On the 13th postoperative day the monkey appeared entirely normal in his behavior, showing no evidences of hypotonicity and no action tremor. 
Third operation (1-25-54) and postoperative testing. The procedures were the same as in the first operation except that the needle was inserted in the left globus pallidus in accordance with previously determined readings. The monkey succumbed to anesthesia.

Microscopic report. This material was checked microscopically only for the location of the lesions. There are degenerated fibers in the ansa lenticularis on the right and destructive lesions in both red nuclei.

\section{Monkey No. 4}

This male Macaca mulatta, weighing $5.3 \mathrm{~kg}$, was curious and active and had a negative neurological examination.

First opertion (1-23-54) and postoperative testing. The animal was anesthetized and placed in the stereotaxic instrument. The needle was placed in the right globus pallidus in accordance with previously determined readings. The stimulation varied from 3-6 volts. No responses were obtained from stimulation except at the most caudomedial point where, at all depths, there was interference with respiration. Lesions were placed at all readings. No immediate effects were noted except at the levels where respiratory changes had been noted on stimulation. At such levels respiration ceased and the placing of the lesions were discontinuel. On the second postoperative day the animal was mildly lethargic and apathetic. On the 6 th postoperative day, he had a very fine shivering of both lower extremities which only occurred when the animal was cold. This fine movement did not appear to be a tremor. He was easily caught and much more docile than preoperatively. He continued to be apathetic. On the 9 th postoperative day he demonstrated mild, generalized convulsive movements when attempts were made to catch him.

Second operation (2-29-54). The animal was anesthetized and placed in the stereotaxic instrument. A bone flap was turned but the needle was not inserted in the brain because the readings did not check properly. The monkey was allowed to recover from the anesthesia.

Third operation (2-2-54) and postoperative testing. The operative procedures were the same as in the first operation except that the needle was inserted in the left globus pallidus. Some difficulty in maintaining normal respiration was encountered, due, apparently, to the anesthetic rather than the lesions. On the 6th postoperative day a fine generalized tremor was present in all 4 extremities which increased when the monkey was excited. There was some incoordination in movement of the extremities but the tonus was normal. This tremor appeared to be more in the nature of an emotional response 
than of a typical basal ganglion tremor. On the 14th postoperative day the neurological signs had not changed.

Fourth operation (2-16-54) and postoperative testing. The operative procedures were the same as in the first operation except that the neddle was inserted in the right red nucleus and the adjacent area of the tegmentum. With all readings, stimulation increased the tremor in the left hand and produced a temporary rigidity of the left arm. Accompanying these signs was a marked slowing of the respiration. Lesions were placed at all readings in the usnal manner. On the third postoperative day the animal exhibited a hypotonia of the right hind leg, a weak grasp of the left foot and some difficulty with the left lower extremity in walking. A generalized, rapid, alternating action tremor was present in all 4 extremities. On the 13th postoperative day the monkey had mild incoordination in all movements and oceasional generalized, mild clonic convulsions during which he shook all over for a few seconds but did not fall. The tremor was greatly reduced and the general muscle tone was normal.

Fifth operation (3-1-54) and postoperative testing. The operative procedures were the same as in the first operation except that the needle was inserted in the left red nucleus and the adajcent area of the tegmentum. At all but the most caudal readings, stimulation produced an extension of the right arm at the wrist and flexion of the right fingers. A tremor of the right hand also appeared. Respiration was again slowed during the stimulation. Lesions were placed at all readings. On the 10 th postoperative day the monkey showed marked loathness to move. He had mild rigidity and tremor in all 4 extremities. This condition was still present on the 25th and 31st postoperative days. On the 61st postoperative day he exhibited some reduction in tremor but the rigidity was maintained. $\mathrm{He}$ was still loath to move but, when he could be persuaded to do so, he showed marked incoordination.

Sixth operation (4-30-54) and postoperative testing. The procedures were the same as in the previous operations except that the needle was inserted in the right nucleus ventralis lateralis of the dorsal thalamus. At the anterior readings marked tremor appeared in both arms and choreoathetoid movements of both upper extremities increased. In the posterior readings, stimulations suggested involvement of the internal capsule. Lesions were placed only at the anterior readings. On the 21st postoperative day the animal showed general incoordination and generalized hypotonicity. No tremor was apparent after the operation of April 30. Myoclonic convulsions involving all extremities occurred occasionally. On the 24 th postoperative day the condition of the monkey remained unchanged. 
Seventh operation (5-24-54) and postoperative testing. The operative procedures were the same as in the previous operations except that the needle was inserted in the left nucleus ventralis lateralis of the dorsal thalamus. Stimulation at the more anterior readings gave a fine tremor in the right arm and right leg. Stimulation more caudalward indicated that the needle was in the internal capsule. Lesions were placed at the anterior readings. On the 8 th postoperative day the monkey showed less rigidity than before the last operation and had no tremor. He still had occasional myoclonic attacks similar to those seen in patients with Wilson's lenticular degeneration.

Microscopic report. On 6-2-54 the monkey was sacrificed and perfused and the brain prepared by the Marchi technique. In this monkey lesions are present in the caudate nucleus on each side (fig. 6), in the globus pallidus bilaterally (fig. 7, on the left) and in both subthalamic nuclei (fig. 7). There is degeneration in the pallidohypothalamic tract and in the subthalamic fasciculus. There is evidence of diffuse degeneration in both red nuclei and both rubrospinal tracts.

\section{Monkey No. 5}

This animal was an active, alert female Macaca cynmologus who was noisy and very quick in her responses. The neurological examination was negative. She weighed $3.7 \mathrm{~kg}$.

First operation (2-9-54) and postoperative testing. The animal was anesthetized and placed in the stereotaxic instrument. The needle was inserted in the right red nucleus in accordance with previously determined readings. Stimulation was from 3-6 volts. No responses were obtained on stimulation except when the most caudolaterally placed reading was used. Then the respirations ceased but returned when the stimulation was discontinued. No lesion was placed at this most caudolateral location; otherwise lesions were made at all the points stimulated.

Immediately after the operation the right pupil was larger than the left. Muscle tone was reduced in the left arm and left leg. On the second postoperative day the pupils were equal. The monkey had a weak grasp in the left foot, but the hypotonus was less noticeable in both left extremities than at the first postoperative testing, although still present. Placing movements with the left hind foot were incoordinated but she moved about the cage with no evident difficulty. On the 10th postoperative day, the monkey still had some hypotonia in the left hind leg, but none could be demonstrated in the left forelimb. On the 14th postoperative day the monkey had the same signs as on the previous examination. 
Second operation (2-25-54) and postoperative testing. The procedures were the same as for the first operation except that the needle was placed in the left red nucleus. On stimulation there was some elevation and retraction of both shoulders at all readings. Stimulation at the more caudal readings produced a transient, fine, contralateral tremor and the right arm became rigid. Lesions were made at all readings. While these lesions were being placed at the more caudal readings, the rigidity of the right arm disappeared. Immediately postoperatively the monkey appeared normal in all respects, except for jerky movements of the head and neck.

Third operation (3-18-54) and postoperative testing. The procedures were the same as for the first operation except that the needle was inserted in the right red nucleus and the area dorsal and lateral to it. On stimulation some coarse movements of the right upper and lower extremities were obtained, associated with a marked slowing of respiration. No changes of any significance resulted on placing the lesions except temporary slowing of respiration. On the 7 th postoperative day this monkey showed loathness to move and hypotonicity in the left extremities. She had no tremor but occasionally showed a myoclonic convulsion. On the 14th postoperative day the findings were the same as on the 7 th day.

Fourth operation (4-1-54) and postoperative testing. The procedures were the same as for the first operation except that the needle was inserted in the left red nucleus and the area dorsal and lateral to it. Stimulation produced marked tremor of both upper extremities. While the lesion was being placed, athetoid movements of the right arm and rigidity of all 4 extremities were apparent. These signs disappeared when the destructive current was turned off. At the end of the operation the monkey was somnolent and had a ptosis of the right eye (partial oculomotor involvement). All 4 extremities exhibited regidity; this rigidity was greater on the right. On the first postoperative day the animal was extremely loath to move and still somewhat sleepy. Mild rigidity and a fine action tremor were evident in all 4 extremities. She fell to the left as she walked about the cage and her head was flexed toward her left shoulder. She had athetoid movements in both upper extremities. On the 7 th postoperative day the signs were the same.

Fifth operation (4-8-54) and postoperative testing. The procedures were the same as for the first operation except that the needle was inserted in the right nucleus ventralis lateralis. Stimulation indicated that the internal capsule was involved and no lesions were placed.

Sixth operation (4-14-54) and postoperative testing. The same procedure used in the 5th operation was repeated but with unsatis- 
factory results on stimulation. No lesions were placed. On the second postoperative day examination disclosed the same signs as after the 4 th operation.

Microscopic report. The monkey was sacrificed on 5-21-54, and the brain was prepared by the Marchi technique. In the brain of this monkey there are bilateral lesions in the nucleus ventralis lateralis (fig. 8) and the nucleus ventralis anterior (fig. 8) of the dorsal thalamus. One lesion, which is situated too for medially, destroyed a part of the midline nuclear gray of the dorsal thalamus. Both red nuclei show lesions; the right lesion involves crossing fibers of the oculomotor root (fig. 9, right). There are also areas of destruction in the deep tegmental gray, lateral and dorsolateral to the red nucleus (fig. 10, right) on either side of the brain. Degenerated rubrospinal and tegmentospinal fascicles can be traced caudalward through the brain stem (fig. 10).

\section{Monkey No. 6}

This male Macaca cynmologus was an alert animal with a negative neurological examination. His weight was $3.2 \mathrm{~kg}$.

First operation (3-11-54) and postoperative testing. This animal was anesthetized and placed in the stereotaxic machine. The needle was inserted in the left globus pallidus and in the adjoining left internal capsule, in accordance with previously determined readings. For stimulation the current had a voltage of 3-6 volts. On stimulation, the more medial regions gave movements consistent with internal capsule involvement. No movements were elicited at the most rostral and the most caudal readings. At internal capsule levels, through the genu and rostral part of the posterior limb, contralateral face, wrist and hand movements were obtained. Farther caudally, contralateral upper arm movements succeeded the wrist movements. At other points (presumably outside of the internal capsule) no effects of the stimulations were noted during the operation. Lesions were placed in all areas stimulated. On the first postoperative day, the monkey showed a flaceid paresis of the right forelimb with a marked loss of fine movements in the involved hand. There were increased deep reflexes in the right upper extremity and the suggestion of a Babinski in the right lower extremity but no other evidences of pyramidal tract involvement. On the 5 th postoperative day the monkey had weakness and spasticity of all 4 extremities. This condition continued until the 8 th day when the monkey died.

Mioroscopic report. Postmortem examination demonstrated an abscess at the spinomedullary junction. Slides stained for acid fast bacteria showed the presence of numerous bacteria of this type. 
Probably the lesion was a tuberculous abscess. Grossly there is a small lesion in the ventromedial tip of the globus pallidus which extends ventral to it. Some fibers of the ansa lenticularis are involved. There are needle tracks in the internal capsule.

\section{Monkey No. 7}

This active, alert male Macaca mulatta had a negative neurological examination but appeared underweight and thin. He weighed $2.3 \mathrm{~kg}$.

First operation (5-4-54) and postoperative testing. The animal was anesthetized and placed in the stereotaxic instrument. The needle was inserted in the right globus pallidus and the underlying white matter in accordance with previously determined readings. The current used for stimulation had a voltage of 3-6 volts. At the most anteromedial points, stimulation gave bilateral shoulder shrugs. Otherwise no responses were obtained. The monkey never completely recovered from the operation. He was dull, loath to move and gradually went into coma. He succumbed on 5-8-54.

Postmortem report. Examination showed tuberculosis of the lungs. The brain was not removed.

Monkey No. 8

This female Macaca mulatta was an aggressive, belligerent and active animal which had a negative neurological examination. She weighed $5.3 \mathrm{~kg}$.

First operation (9-28-54) and postoperative testing. The animal was anesthetized and a craniotomy was performed to expose the left orbital surface. The area indicated by $X$ on figure 11 was removed by suction, the dura closed and the extradural tissue sutured in layers. The skin was closed with interrupted sutures. On the first and 8th postoperative days, examination disclosed no changes in behavior and no neurological signs.

Second operation (10-5-54). The procedures were the same as those employed in the first operation except that the lesion was placed in the right orbital region of the hemisphere. The animal was examined on the second and 5th postoperative days and no changes were observed.

Third operation (10-16-54) and postoperative testing. The operative procedures were the same as those employed for the first operation except that the tip of the right temporal pole was exposed and removed with a sucker. During the first 24 hours after operation this monkey was markedly lethargic. When stimulated she would open her eyes 
and sit up but as soon as the stimulation ceased she closed her eyes and went back to sleep.

Mioroscopic report. The animal was sacrificed on 12-19-54 and the brain was prepared by the Marchi technique. The Marchi material was not suitable for microscopic study but grossly there were lesions present on the right and left surfaces of the orbital gyri and at the tip of the right temporal pole (see fig. 11).

\section{Monkey No. 9}

This female Macaca cynmologus was noisy, curious and quick to respond. The neurological examination was negative. She weighed $2.3 \mathrm{~kg}$.

First operation (10-23-54) and postoperative testing. The animal was anesthetized and a craniectomy was performed to expose the tip of the right temporal lobe. The medial part of the temporal pole was removed by suction. Examination on the first and 12 th postoperative days showed no changes from the preoperative tests.

Second operation (11-5-54) and postoperative testing. The operative techniques employed were the same as in the previous experiments. The tip of the left temporal pole and part of the amygdala were removed by suction. The monkey was examined at intervals from the first to the 34th postoperative days. At no time were any changes in behavior or any neurological signs demonstrable.

Microscopic report. The animal was sacrificed on 12-19-54 and the brain was prepared by the Marchi technique. The Marchi material was unsatisfactory. This series was used merely to locate the extent of the cortical ablation.

\section{DISCUSSION}

This paper is an attempt to study experimentally, by irritative and destructive lesions, involuntary movements, rigidity and loathness to move. Any of these signs, or all of them, may characterize a patient with a Parkinsonian syndrome.

An action tremor was obtained in several monkeys following stimulation or destruction of the red nucleus and of the regions adjoining it dorsolaterally. The tremor following the destruction was of less amplitude than that resulting from stimulation. It was increased in bilateral as compared with unilateral lesions. It tended to decrease gradually during the postoperative period. Some evidence of tremor persisted for months. This tremor could be elicited not only during 
movement but also following activity, although it was not observed in a completely resting monkey. Therefore it was not a true "resting" tremor.

By stimulation and destruction of nucleus ventralis lateralis of the dorsal thalamus, a similar action tremor was obtained, which again increased when the lesions were bilateral. It also persisted for some time after destructive lesions, gradually decreasing in intensity as the postoperative period lengthened. Again, although it could be elicited during activity of the monkey, and following such activity, it could not be obtained in a monkey which had been quiet for a long time. Therefore it also was considered not to be a true "resting" tremor.

In the monkeys experimented upon, tremor was never elicited from stimulation of basal ganglia alone. One monkey which had had destructive lesions in the midbrain tegmentum at an earlier date showed a slight but persistent tremor following a destructive lesion of the globus pallidus. In no case did the lesions of the basal ganglia involve all of these areas and it is possible that larger lesions of these ganglia (or lesions involving more of the putamen) might have produced better evidence of tremor.

As has been emphasized, the tremor obtained in this series of experiments has been an action tremor-essentially a cerebellar tremor. It is significant that the stimulative and destructive lesions, which involved the red nucleus, the tegmental area dorsal and lateral to it and the nucleus ventralis lateralis of the dorsal thalamus, are along the course of the dentorubral, cerebellotegmental, and dentothalamic pathways, respectively.

It should be mentioned that the characteristic tremor in the Parkinsonian syndrome is a resting tremor. It is possible that the rigidity which characterizes patients with Parkinson's disease and makes it difficult for them to perform voluntary acts may inhibit the tremor (Wilson, '29). The monkeys in these experiments never exhibited a very marked degree of rigidity. 
In the midbrain tegmentum of the primate there is a balancing of the impulses from various areas. The basal ganglia discharge to each red nucleus is through the ansa lenticularis and the lenticular fasciculus (Woodburne, Crosby and McCotter, '46). The additional motor areas project impulses to this tegmental region over a great range of corticostriatotegmental systems (Crosby, '56) and corticotegmental paths (Crosby and Henderson, '48; Crosby, '56). The cerebellum discharges to and through the same tegmental areas over ascending paths of the brachium conjunctivum (Rand, '54; Carrea and Mettler, '54). The interrelations of the various systems produce a balancing of discharges that regulates tonus and movements. Lesions in any part of the system may produce an imbalance. Additional lesions may shift the balance in another direction. The hypertonicity that occurred with lesions in the midbrain at or behind red nuclear levels apparently was due to the destruction of fibers of the superior cerebellar peduncle (see also Carrea and Mettler, '54). The rigidity and increased tonus present in Monkey No. 2 became evident when the region in front of the red nucleus was also invaded, suggesting that a change in imbalance had occurred when the paths from the cerebral hemispheres (both basal ganglia and additional motor areas) were also involved.

Finally, lesions in the globus pallidus which extend ventral to it involve pathways from the orbital and, most particularly, the temporal region (as Laursen, '55, also found) or involvements of the orbital and inferior temporal cortical areas produced monkeys which showed great loathness to move. They could be photographed with the cage door wide open. They were apathetic and fell asleep easily even with food in front of them. This type of behavior is seen in some, but not all, patients with the Parkinsonian syndrome. The results reported here and by Laursen ('55) for basal ganglia would suggest that patients showing such loathness to move have involvement of the hypothalamic pathways ventral to the basal ganglia as well as lesions in the ganglia. 
These experiments illustrate the fact that in many involvements of the nervous system the balance between the various portions is upset. The resulting syndrome then may represent over-function of uninjured areas rather than deficits from regions destroyed. Moreover, signs or symptoms of a given syndrome may be due to involvement of fibers of passage through or adjacent to the area rather than destruction of the recognized site of the lesion.

\section{SUMMARY}

This study was carried out on Macaca mulatta and Macaca cynmologus. The deep lesions were made by use of the stereotaxic apparatus. The cortical lesions were produced by direct ablation of the areas with a sucker following craniotomies in the desired regions. The animals were tested preoperatively and postoperatively for involuntary movements, hypertonicity, motor involvement and reaction to their surroundings.

After sacrifice, in most cases, the brains were perfused and checked grossly for evidence of pathological changes. The brains in which the timing was suitable were prepared by the Marchi technique and examined for location and extent of the lesions. In some cases it was possible to follow degenerated fiber systems.

Action tremor of essentially the cerebellar type was obtained on stimulation and/or destruction of the red nucleus, the tegmental areas lateral and dorsolateral to it and the nucleus ventralis lateralis of the dorsal thalamus. This tremor was increased in bilateral lesions and decreased somewhat as the postoperative period lengthened. Action tremor of essentially similar type was increased on destruction of the globus pallidus bilaterally in a monkey which had had a previous tegmental lesion.

Mild rigidity was obtained with bilateral globus pallidus lesions in one monkey which already had tegmental lesions. In no monkey was all the globus pallidus destroyed bilaterally. 
Loathness to move, apathy and drowsiness characterized two monkeys in which the bilateral lesions involved the corticohypothalamic system ventral to the globus pallidus as well as the pallidum itself. Similar but less marked apathy was obtained with cortical ablations which removed portions of the temporal and/or the orbital cortex.

The author wishes to express his indebtedness to Dr. Elizabeth C. Crosby of the Department of Anatomy, University of Michigan, whose generous assistance and encouragement were invaluable. The author also wishes to thank Mr. George Smith for technical assistance in preparing the photographs.

\section{LITERATURE CITED}

ArtËns Kappers, C. U., G. C. Huber and E. C. Crosby 1936 The comparative anatomy of the nervous system of vertebrates, including man. The Maemillan Company, New York. 2 vols.

ARING, C. D., AND J. F. Fulton 1936 Relation of the cerebrum to the cerebellum. II. Cerebellar tremor in the monkey and its absenee after removal of the principal excitable areas of cerebral cortex (areas 4 and $6 a$, upper part). III. Accentuation of cerebellar tremor following lesions of the premotor area (area 6a, upper part). Arch. Neurol. and Psychiat., 35 : $439-466$.

Carpenter, M. B., J. R. Whithier and F. A. Mettler 1950 Tremor in the rhesus monkey produced by diencephalic lesions and studied by graphic method. J. Comp. Neur., 98: 1-12.

Carrea, R. M. E., aND F. A. MetTler 1954 The anatomy of the primate brachium conjunctivum and associated structures. J. Comp. Neur. 101: 565-686.

1955 Functions of the primate conjunctivum and related structures. J. Comp. Neur., 102: 151-322.

CRosBY, E. C. 1956 The role of the midbrain as a part of the discharge paths from higher centers.

Crosbr, E. C., AND J. W. Henderson 1948 The mammalian midbrain and isthmus regions. II. Fiber connections of the superior colliculus. B. Pathways concerned in automatic eye movements. J. Comp. Neur., 88: 53-92.

CRosbi, E. C., AND R. T. WOODBurne 1951 The mammalian midbrain and isthmus regions. Part II. The fiber connections. C. The hypothalamotegmental pathways. J. Comp. Neur., 94: 1-32.

Dafenport, H. A., AND S. W. Ranson 1930 The red nucleus and adjacent cell groups. Arch. Neurol. and Psychiat., 24: 257-266. 
De Jong, R. N. 1950 The Neurologic Examination. Paul B. Hoeber, Inc., New York.

DENNY-BRown, D 1946 Diseases of the basal ganglia and subthalanie nuclei. Reprinted from Oxford Loose-leaf Medicine. Oxford University Press, New York, 115 pp.

Ferraro, A., and W. E. Barrera 1936 The effects of lesions of the superior cerebellar peduncle in the Macacus rhesus monkey. Bull. Neur. Inst, New York, 5: 165-179.

Grinker, R. R., AND P. C. Bucy 1949 Neurology. 4th Ed., Charles C Thomas, Springfield, Illinois, $1138 \mathrm{pp}$.

Holmes, G. 1904 On certain tremors in organic cerebral lesions. Brain, 27 : $327-375$.

Huber, G. C., E. C. Crosbr, R. T. Woodburne, L. A. Grelitan, J. O. Brown and B. Tamtear 1943 The mammalian midbrain and isthmus regions. Part I. The nuclear pattern. J. Comp. Neur., 78: 129-504.

INGRAM, W. R., S. W. RANSON, AND R. W. BARRIS 1934 The red nucleus. Its relation to postural tonus and righting reactions. Arch. Neurol. and Psychiat., g1: 768-786.

Ingram, W. R., S. W. Ranson, F. I. Hannett, F. R. Zeiss and H. Terwilliger 1932 Results of stimulation of the tegmentum with the Horsley-Clarke stereotaxic apparatus. Areh. Neurol. and Psyehiat., 28: 513-541.

JENKNER, F. I., AND A. WARD, JR. 1953 Bulbar reticular formation and tremor. Areh. Neurol. and Psychiat., 70: 489-502.

Keller, A. D., AND W. K. HARE 1934 The rubrospinal tract in the monkey. Effects of experimental section. Arch. Neurol. and Psychiat., 32: $1253-1272$.

KENNARD, M. A. 1944 Experimental analysis of the functions of the basal ganglia in monkeys and chimpanzees. J. Ncurophysiol., $7: 127-148$.

KoDama, S. 1926 2. Über die sogenannten Basalganglien. (Morphogenetisehe und pathologisch-anatomische Untersuchungen). II. Pathologisch-anatomische Untersuchungen mit Bezug auf die sogenannten Basalganglien und ilıre Adnexe. Schweiz. Arch. f. Neurol. u. Psychiat., 20: 209-261. 1929 2. Über dic sigenannten Basalganglien. (Morphogenetisebe und pathologisch-anatomische Untersuchungen). II. Pathologisch-anatomische Untersuchungen mit Bezug auf die sogenamnten Basalganglien und ihre Adnexe. B. Über die Faserverbindungen zwisehen den Basalganglien und ihre Adnexen, sowie den übrigen subkortikalen Kerngebieten beim Mensehen, nebst einigen experimentellen Mitteilungen. Ibid., 23: 38-100, 179-265.

LAURSEN, A. M. 1955 An experimental study of the pathways from the basal ganglia. J. Comp. Neur., 108: 1-26.

METTLER, F. A. 1942 Relation between pyramidal and extrapyramidal function. Res. Publ. Assn. nerv. ment. dis., 21: 150-227.

Mettler, R. A., AND J. R. Whitrier 1947 The experimental production of abnormal involuntary movements in primates. Trans. Amer. Neurol. Assoc., 72: 96-101, 190-192. 
MoRgan, L. O. 1927 The corpus striatum. A study of secondary degenerations following lesions in man and of symptoms and acute degenerations following experimental lesions in cats. Arch. Neurol. and Psychiat., 18: $495-549$.

Parkinson, J. 1817 An Essay on Shaking Palsy. Reprinted in Medical Classics, 2: 964-997, June 1938. The Williams and Wilkins Company, Baltimore, Maryland.

RAND, R. W. 1954 An anatomical and experimental study of the cerebellar nuclei and their efferent pathways in the monkey. J. Comp. Neur., 101: 167-223.

RaNson, S. W, AND S. W. RaNson, JR. 1942 Efferent fibers of the corpus striatum. Res. Publ. Assn. nerv. ment. dis., 21: 69-76.

Ranson, S. W., S. W. Ranson, JR., AND M. Ranson 1941 Fiber connections of corpus striatum as seen in Marchi preparations. Arch. Neurol. and Psychiat., 46: 230-249.

Whittier, J. R., AND F. A. METTLeR 1949 Studies on the subthalamus of the rhesus monkey. II. Hyperkinesia and other physiologic effects of subthalamie nucleus of Luys. J. Comp. Neur., 9o: 319-372.

WILson, S. A. K. 1912 Progressive lenticular degeneration; a familial disease associated with eirrhosis of the liver. Brain, 34: 295-509.

1914 An experimental research into the anatomy and physiology of the corpus striatum. Brain, $36: 427-492$.

1929 Modern Problems in Neurology. William Wood and Company, New York, 364 pp.

1941 Neurology. Edited by A. Ninian Bruce. The Williams and Wilkins Company, Baltimore, 2 vols.

Woodburne, R. T., E. C. Crosby and R. E. McCotTer 1946 The Mammalian midbrain and isthmus regions. Part II. The fiber connections. A. The relations of the tegmentum of the midbrain with the basal ganglia in Macaca mulatta. J. Comp. Neur., 85: 67-92. 


\section{PLATES}

\section{ABBREVIATIONS FOR FIGURES}

aqueduct: eerebral aqueduct

capsula inter., ant. limb: capsula interna, anterior limb

capsula inter., post. limb: capsula interna, posterior limb

chiasma opt.: chiasma opticum comm. ant.: commissure anterior comm. post.: commissure posterior corpus call.: corpus callosum dec. brach. conj.: decussation brachium conjunctivum deep teg. gray: deep tegmental gray fas. subthal.: fasciculus subthalamus glob. pall.: globus pallidus glob. pall. ventromed. tip: globus pallidus ventromedial tip

lemn, med.: lemniseus medialis

lent. fas.: lenticular fasciculus midbr.: midbrain

nuc. ant. thal.: nucleus anterior thalami

nuc. caudatus: nucleus eaudatus nue. gen. lat.: nucleus geniculatus lateralis

nuc. gen. med.: nucleus geniculatus medialis

N. III : third nerve roots

nue. dorsomed. thal.: nueleus dorsomedialis thalami

nue. lat. thal.: nueleus lateralis thalami

nuc. rub.: nucleus ruber

nuc. subthal.: nucleus subthalamus

nuc. vent. ant.: nucleus ventralis lateralis

nuc. vent. post.: nucleus ventralis posterior

stria medull.: stria medullaris thalami ped. cerebri: pedunculus cerebri sub. nigra: substantia nigra thal. dors.: thalamus dorsalis tr. teg-sp.: tractus tegmentospinalis tr. rubrospinalis: tractus rubrospinalis

PLATE 1

\section{EXPLANATION OF FIGURES}

1 and 2 Photomicrographs of selected sections through the rostral part of the basal ganglia of Monkey No. 1. Small lesions are shown in the caudate nucleus, the posterior limb of the internal capsule and the globus pallidus. Macacus eynmologus, Marchi preparations. $\times 2.5$.

3 A photomicrograph of a section through the forebrain of Macaca mulatta (Monkey No. 2) at the level of the anterior nuclei and the anterior end of the ventral nuclear group of the dorsal thalamus. The anterior part of the posterior limb of the internal capsule and the ventromedial tip of the globus pallidus are evident in the figure. There is a lesion in the tip of the globus pallidus. Marchi preparations. $\times 2$. 

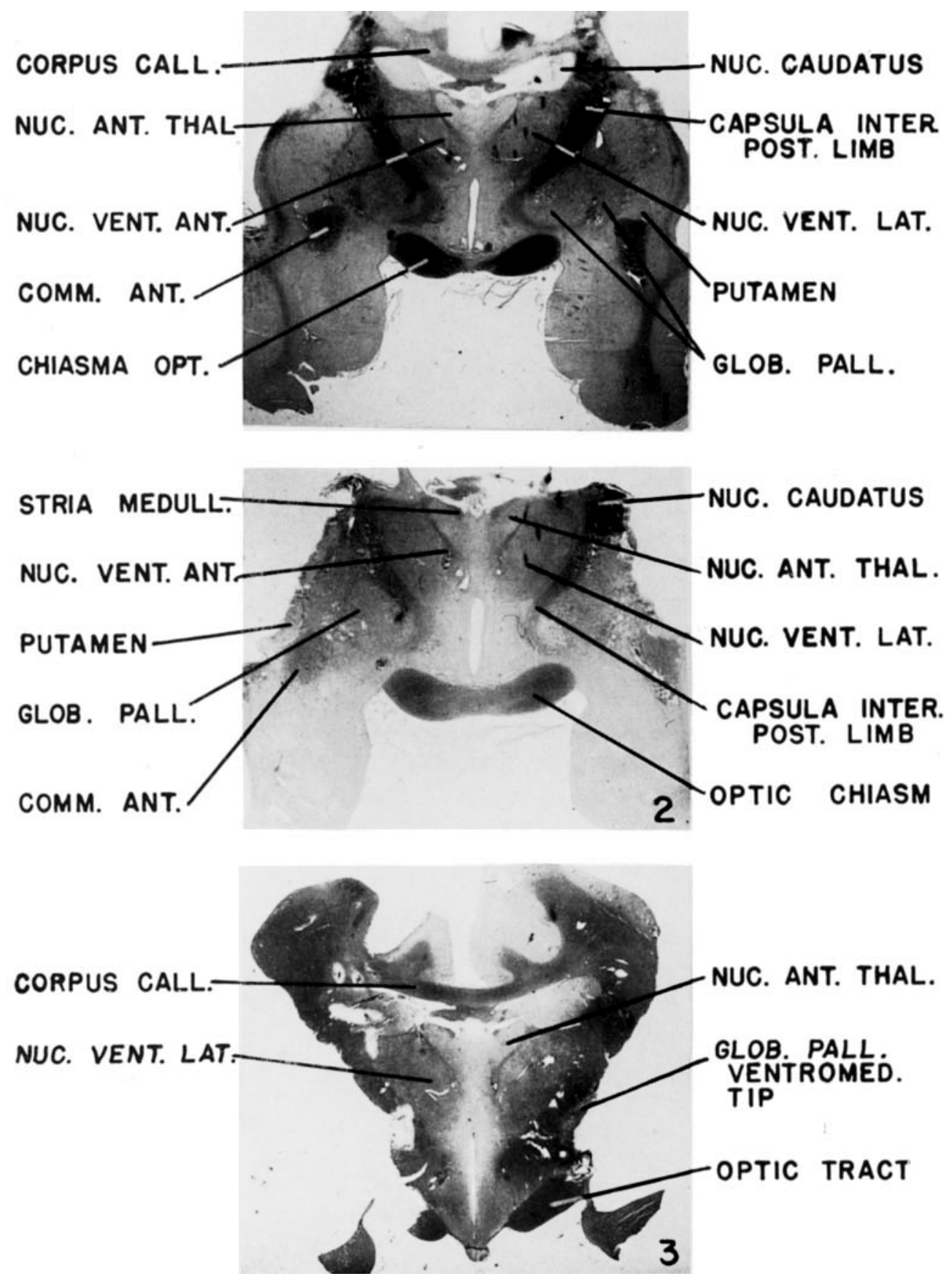


\section{PLATE 2}

EXPLANATION OF FIGURES

4 Photomicrograph of a section of the same brain shown in figure 3 but taken somewhat farther caudalward. The section is through the mucleus ventralis lateralis and the begiming of the nucleus ventralis posterior of the dorsal thalamus. The location of a lesion involving the ventromedial part of globus pallidus, the region immediately ventral to it and the optie tract is shown on the right. Marrhi preparations. $\times 2$.

5 Photomierograph through the midbrain tegmentum. The section is obliquely cut so that the dorsal part of the field passes through the dorsal thalamus and the ventral part through the transition from midbrain to pons. The lesion involving the red nucleus, bilaterally, are very clear. Marchi preparations. $\times 2$.

6 Photomicrograph of a section through the rostral part of the forebrain of Monkey No, 4 (Macaca mulatta). 'The degenerations in the caudate nuclei are evident. Marehi preparations. $\times 2.5$. 

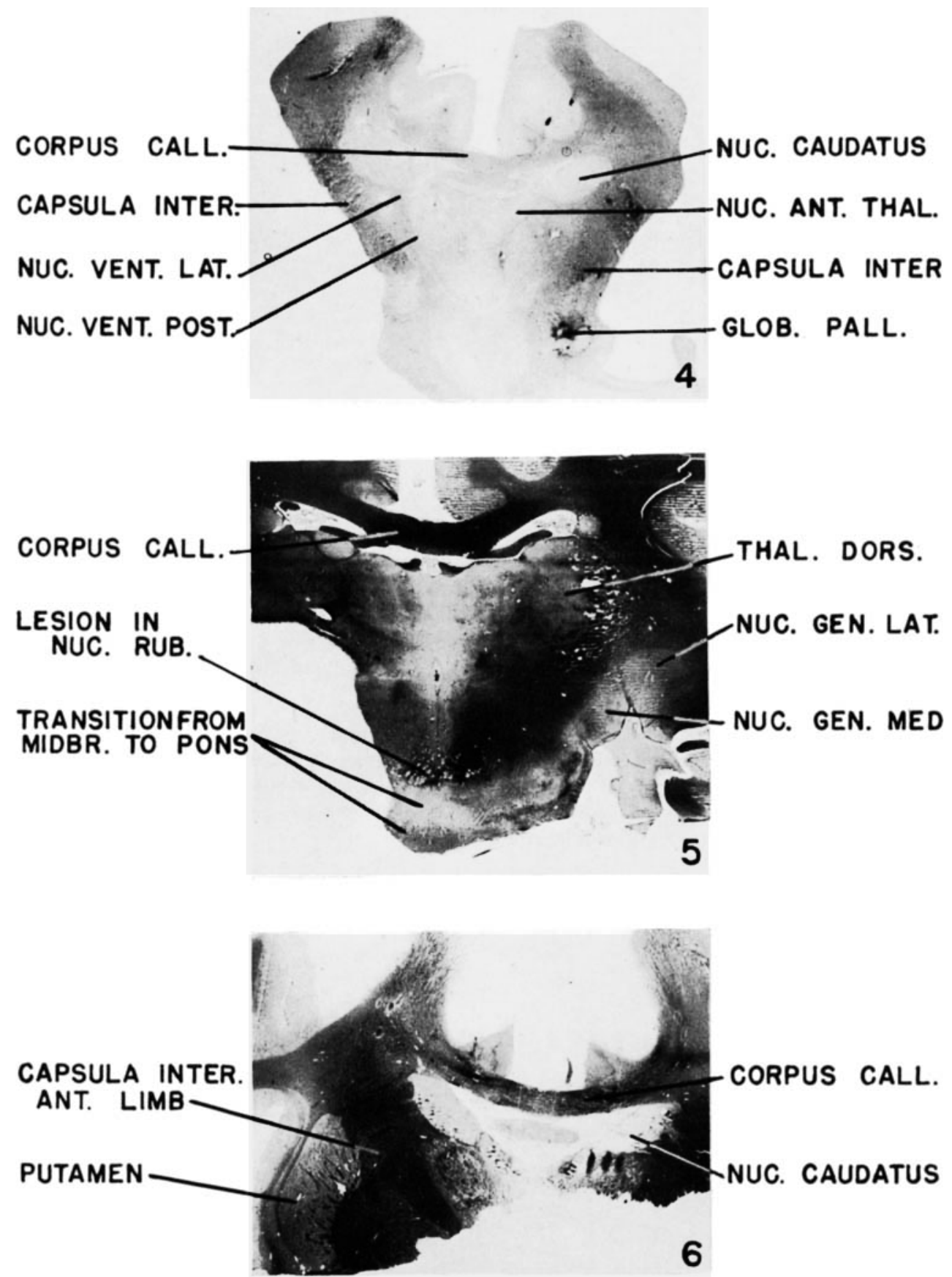
PLATF 3

EXPLANATION OF FIGURES

7 Photomierograph of a section from the same brain shown in figure 6 but located through diencephalic levels. The figure shows the lesion in the globns pallidus on the left and in both subthalamic nuclei. Marchi preparations. $\times$ 2.5.

8 Photomicrograph through the diencephalon of Monkey No. 5 (Macalum eynmologus) at a plane cutting the nucleus ventralis anterior dorsaly and the optie traets just beyond the optie ehiasma ventrally. Lesions are shown in the nucleus ventralis anterior and the nucleus ventralis lateralis of both sides. Marchi preparations. $\times 2.5$.

9 Photomicrograph of a section from the same brain as that shown in figure 8 but taken at the most rostral midbrain levels. The section passes through the posterior commissure dorsally and the emerging oculomotor roots ventrally. A lesion is present in the red nucleus on the right whieh also involves the right oculomotor root. Marehi preparations. $\times 2.5$. 

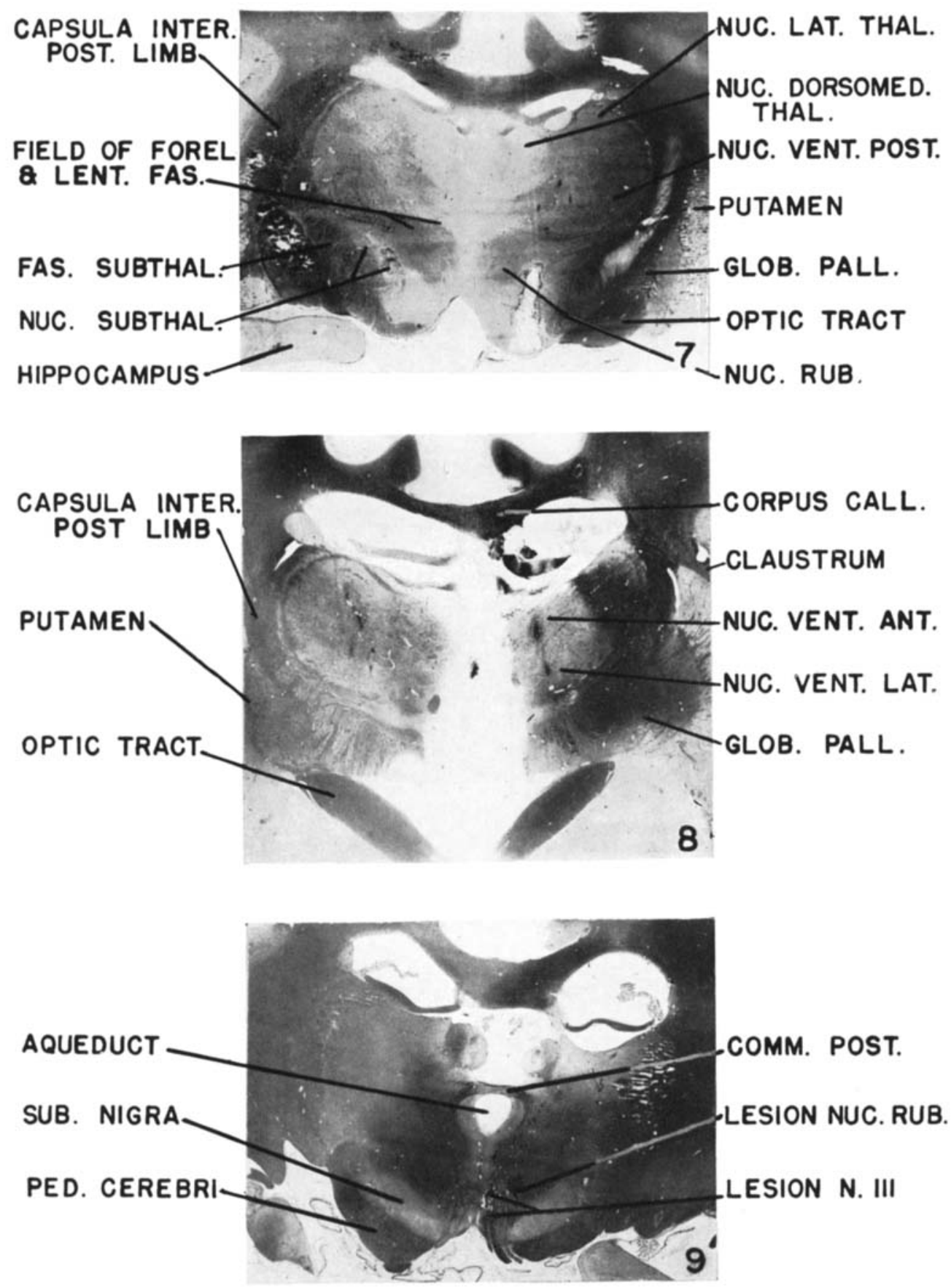
PLATE 4

\section{FXPLANATION OF FIGURES}

10 Plotomicrograph of a section through the brain of Monkey No. 5 (Macacus eymmologus) which jasses through the superior colliculi dorsally and the base of the pons ventrally. This section was reversed so that the lesions on the right side of the brain are on the left in the figure. It shows Marchi granules in the region of the resion of the ruhrospinal tract and a tegmentospinal system on the loft and a lesion in the deep tegmental gray on the right. Marchi preparations. $\times 18$.

11 This figure is a photomierograph of a section through the rostral ent of the eerebral hemispheres of Monkey No. 8. The material did not respond satis. factorially to the Marchi teehnique but the site of the lesion is indicaten in the illustration. Macacus eymmologus. Marehi preparations. $\times 2.5$. 

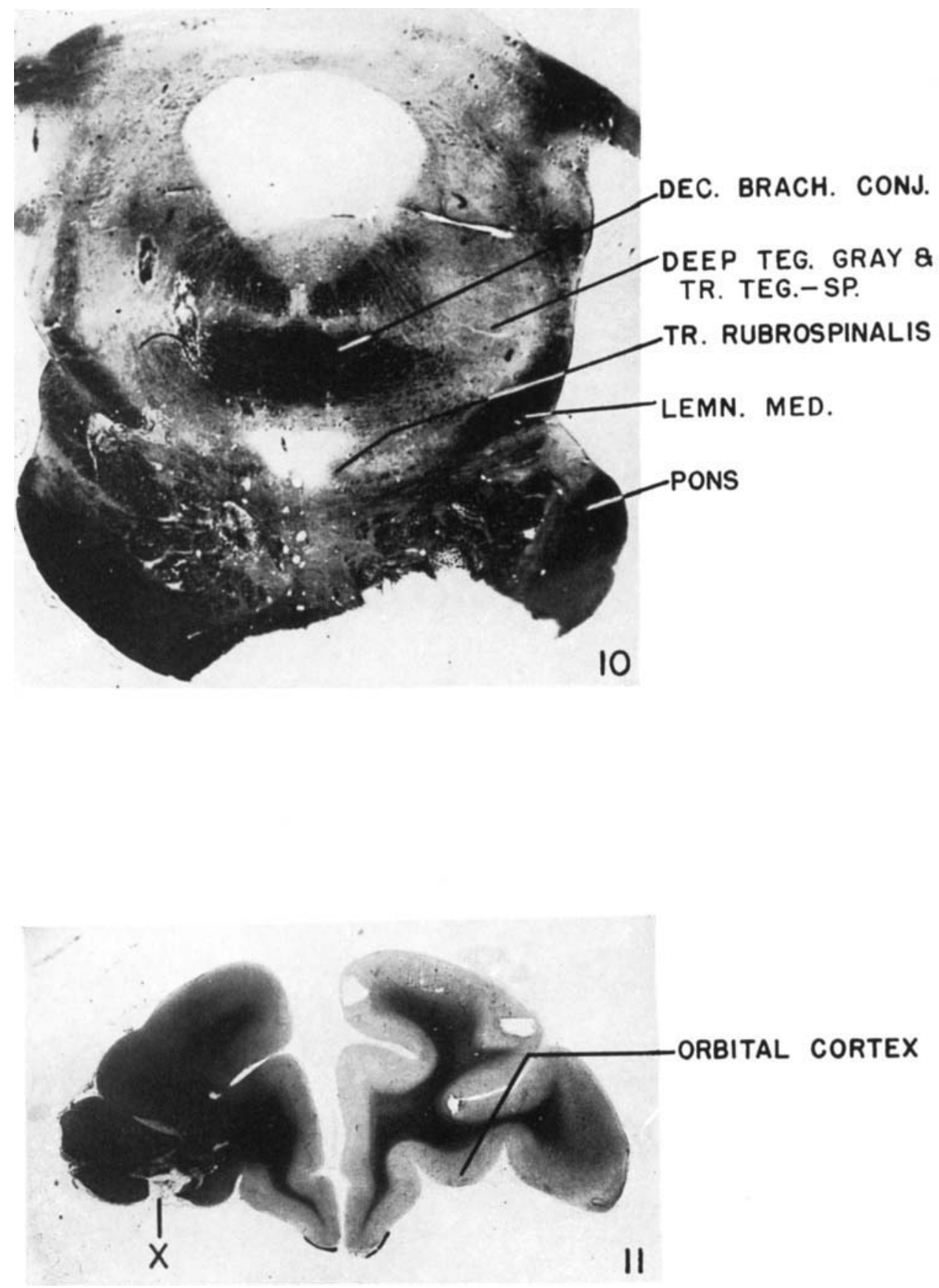